\title{
ANTIVIRAL ACTIVITY OF EXTRACTED FRACTION FROM CAMEL URINE AGAINST CORONA AND INFLUENZA A (H1N1) VIRUSES
}

\author{
Al AtTAS, S. A. ${ }^{1}-$ KHORSHID, F. A. ${ }^{1}-$ KAO, M. ${ }^{2}-$ BAHIELDIN, A. ${ }^{*}$ \\ ${ }^{I}$ Department of Biological Sciences, Faculty of Science, King Abdulaziz University \\ Jeddah 21589, Saudi Arabia \\ ${ }^{2}$ Fachtierarzt für Mikrobiologie Fachgebiet II.3 virologische und serologische Diagnostik \\ Landesbetrieb Hessisches Landeslabor (LHL), Druseltalstraße 67-34131 Kassel, Germany \\ *Corresponding author \\ e-mail: abmahmed@kau.edu.sa; phone: +966-506-32-9922 \\ ORCID ID: 0000-0002-6496-7881
}

(Received 30 $0^{\text {th }}$ Mar 2019; accepted $1^{\text {st }}$ Jul 2019)

\begin{abstract}
PMF (a camel urine or PM 701 fraction), is a traditional treatment for many human diseases. Demands for developing clinical treatments against dangerous viruses are increasing. This study aimed to investigate the effects of PMF as a novel pharmaceutical drug in vitro in inducing antiviral and/or virostatic activity against MERS-CoV and influenza A (H1N1) viruses. Infectivity assay was determined by end point dilution titration, infective dose was calculated and PMF virucidal activity was evaluated as a reduction factor. Quantitative virucidal suspension test was performed using TGEV virus, as a model for MERS-CoV, and H1N1 virus. The results indicated that PMF concentration of $20.34 \%$ inactivated 99.5\% of the TGEV virus after $60 \mathrm{~min}$, and $99.9 \%$ after $240 \mathrm{~min}$. The results also indicated that the same PMF concentration inactivated H1N1 virus on Madin Darby canine kidney cells (MDCK/63) by $98.90 \%$ and $99.99 \%$ after 60 and 240 min, respectively. We speculate that copper and zinc elements in PMF might vitally contribute to the antiviral and virostatic activity. In conclusion, PMF was proven to induce antiviral in vitro activity against both viruses, hence, is recommended to use as a therapeutic antiviral agent in the future.
\end{abstract}

Keywords: $P M F, M E R S-C o V, T G E V, H 1 N 1$, virostatic activity

\section{Introduction}

Corona viruses (CoVs) cause a wide range of respiratory and gastric diseases. Most CoVs are RNA viruses, which replicate in epithelial cells of respiratory and digestive tracts (van der Hoek et al., 2004). These viruses enter the cell by viral spike (S) proteins that bind to cellular receptors and facilitate virus-cell membrane fusions. Du et al. (2017) indicated that spike protein is a key target as antiviral mechanism against CoVs. Lin et al. (2017) were able to induce antiviral activity against the virus by resveratrol treatment. Müller et al. (2017) also indicated the successful usage of binase in inhibiting virus genome replication. The diversity of $\mathrm{CoVs}$ is reflected in $\mathrm{S}$ protein variability, which is involved in different receptor interactions and respond to different environmental conditions (Belouzard et al., 2012). A new corona virus was identified during summer of 2012 in Saudi Arabia (Zaki et al., 2012) and named Middle East respiratory syndrome corona virus (MERS-CoV) by International Committee on Taxonomy of Viruses (de Groot et al., 2013). The Middle East respiratory syndrome is a pneumonic illness caused by a novel lineage $\mathrm{C}$ betacoronavirus (CoV). In 2014, a total of 178 MERS cases were confirmed in humans, which resulted in 76 deaths (WHO, 2014). Infection with MERS$\mathrm{CoV}$ can also cause abdominal pain, diarrhea, fever and renal failure (Assiri et al., 2013). 
The virus was found mostly in the lower respiratory tract samples, while low concentrations were found in stool, urine, and blood samples (Drosten et al., 2013). Limited human-to-human transmission has resulted in clusters of cases; the remaining sporadic cases in humans are of zoonotic origin (Assiri et al., 2013). Up to date, both reservoir and intermediate hosts remain unidentified, delaying any success on controlling the virus. MERS-CoV had been spread into eleven countries of the Middle East, North Africa, South Korean and Europe. Therefore, there are global concerns over security, but the Economist report announced that "Concern over security must not slow urgent work, studying a deadly virus is risky; not studying it is riskier" (Economist.com, 2014). The demand for developing clinical treatment against MERS-CoV is increasing, but the strict limitations for using strains of new deadly virus is still slowing down and retards scientific investigations. In this study, we used TGEV virus as a model for MERS-CoV, as both are corona viruses. Transmissible Gastroenteritis Virus (TGEV) belongs to corona viridae family, genus Alphacoronavirus, species Alphacoronavirus (Frieman, 2014). It is an enveloped virus with a positive single stranded RNA genome. TGEV infects pigs and rarely humans. In pigs, mortality rate is close to $100 \%$. The pathology of TGEV is similar to that of other corona viruses. They enter the host by attaching to cell membrane using spike glycoprotein and multiplies in cell lining of small intestine resulting in loss of absorptive cells and shortening of villi. The infected host then loses the ability for digesting food and dies from dehydration (Frieman, 2014).

H1N1 is the subtype of influenza A virus causing swine and human flu (Lim and Mahmood, 2011; Kong et al., 2015). It is an orthomyxovirus harboring the two glycoproteins haemagglutinin and neuraminidase (Du et al., 2017). Up to 2015, more than 40 million people died due to the infection with H1N1 (Kong et al., 2015). Cloning and sequencing of the eight virus genes revealed that human influenza virus is closely related to avian influenza virus with regard to their coding sequences (Taubenberger et al., 2005; Morens and Fauci, 2007; Taubenberger et al., 2007).

Natural products are important source for novel drug therapies of efficient compounds with diverse biological activities and unique chemical structures. Camel urine is known as a traditional treatment of many diseases in Arabs countries (Alghamdi and Khorshid, 2012; Mahboub et al., 2015). The relative density of mature camel urine ranges from 1.02 to $1.07 \mathrm{~g} / \mathrm{dL} ; \mathrm{pH}$ varied between acidic or alkaline; urea level ranged from 18-36 $\mathrm{g} / \mathrm{dL}$ and creatinine level ranged from 0.2-0.5 g/L (Al-Bashan, 2011). Chemical and microscopic examination showed the presence of phosphorus, calcium oxalate and ammonium urate and some epithelial and granular cells (Al-Bashan, 2011). PMF (a camel urine or PM 701 fraction) is a novel pharmaceutical drug that was extracted from PM 701 (lyophilized camel urine) that is able to selectively inhibit the proliferation of cancer cells significantly without affecting normal cells at human cell culture level and animal models (Khorshid, 2008, 2009; Khorshid et al., 2005, 2009, 2011; El-Shahawy et al., 2010). Prospects of the use of therapeutic nanoparticles, nanobodies and nanorods from this natural product was recently explored for cancer therapy (Getachew Alebie et al., 2017).

New treatments cannot be tested directly on humans because they could be potentially dangerous and experiment can be costly. Alternatively, human cell culture and animal models are used traditionally for testing and developing safe dose and working mechanisms of innovative therapies. In this study, we detected the influence of PMF in terms of antiviral activity on TGEV as a model virus on fetal testis cells of swine (ST75/2) and H1N1 virus utilizing Madin Darby canine kidney cell line (MDCK/63). 


\section{Materials and Methods}

\section{Extraction of PMF}

PMF was extracted at the laboratory of King Fahad Medical Research Center, King Abdulaziz University (KAU) in Jeddah, Saudi Arabia as previously described (Khorshid et al., 2009). Then, PMF was transported in IATA-compliant container from Saudi Arabia to Eurovir Institute in Luckenwalde, Germany. The fraction was stored at $2-8^{\circ} \mathrm{C}$ prior testing for virucidal activity against TGEV and H1N1 viruses. The PMF product was tested as a working solution of $25.42 \%(\mathrm{w} / \mathrm{v})$ and $\mathrm{pH}$ of $9.71(0.75 \mathrm{~g}$ of PMF-concentrate was solved with agitation and warming to $37^{\circ} \mathrm{C}$ in $2.95 \mathrm{~mL}$ of aqua bidest). In the test sample, PMF working solution was diluted with a factor of 1:25 due to addition of TGEV or H1N1 suspensions and interfering phosphate-buffered saline substance (PBS).

\section{TGEV and H1N1 virus suspensions}

TGEV strain Toyama was obtained from virus bank of the Bundesforschungsanstalt f. Viruskrankheiten der Tiere; Friedrich Löffler-Institut, InselRiems, Germany, as a model virus for MERS-CoV. Influenza A virus subtype (H1N1) the commonest cause of human influenza (flu) and seasonal Influenza, New Caledonia /20/99, IVR-116 Strain was obtained from virus bank of the Chiron Behring, Marburg/Lahn, Germany. Originally obtained viruses were 10 -fold diluted with MEM; then stored at $-80^{\circ} \mathrm{C}$ until use.

\section{Experimental cells}

ST75/2 cells; fetal testis cells of swine obtained from Robert Koch-Institute, Berlin/ Germany, were used as a target for MERS-CoV virus. They were inspected regularly for morphological alterations and mycoplasmas contamination in which none were detected. For maintenance and growing of the cells, media involved Eagle's minimum essential medium (EMEM), Lot.Nr., glutamine, penicillin/streptomycin, fetal calf serum, PBS and trypsin.

Madin Darby canine kidney reporter cell line MDCK/63; obtained from National reference center for influenza, Robert Koch-Institute, Berlin/Germany, were used as a target for H1N1 virus. Cells survived in living condition with $73^{\text {th }}$ passage of RKI $+3 /+9 /+35$ at $09.07 .2001(=\mathrm{RKI}+0)$. These cells are highly permissive for influenza virus replication and provide a highly specific and sensitive approach for simultaneous detection and isolation of influenza viruses.

\section{Infectivity assay}

To prepare TGEV or H1N1 test virus suspensions, ST75/2 and MDCK/63 cells, that had been cultured with EMEM and $10 \%$ fetal calf serum (FCS), were inoculated with TGEV or H1N1, respectively, in $25 \mathrm{~cm}^{2}$ cell culture flasks. After 48 hours and after induction of cytopathic effect, freezing and thawing were carried out once. Cell debris was removed by centrifugation at $3000 \mathrm{rpm}$ for $10 \mathrm{~min}$ at $4^{\circ} \mathrm{C}$ and supernatant was recovered as test virus suspension and stored in aliquots at $-80^{\circ} \mathrm{C}$.

Infectivity was determined by virus titration of end point dilution titration using microliter process. One hundred $\mu \mathrm{l}$ aliquots of samples were serially diluted with cold EMEM and transferred to four wells of polystyrol 24-well microliter plate with 
performed monolayer of ST75/2 or MDCK cells (placed in each well on the previous day with $100 \mu \mathrm{l}$ aliquots including approx. $1.5 \times 10^{4}$ cells). Infective dose (TCID 50 ) and their $95 \%$ confidence intervals were calculated with Spearman-Karber method (Khorshid et al., 2009). The main samples virus titration was performed and the corresponding virus titer was calculated as previously indicated (Khorshid et al., 2011). The virucidal activity of PMF was evaluated by calculating the decrease in titers in comparison with control untreated titration. The difference is given as a reduction factor (RF). Quantitative virucidal suspension test (QST) was performed following the guideline of DVV and Robert Koch-Institute. Control and virus inactivation screening tests were performed as recently indicated ( $\mathrm{Al}$ Attas et al., in preparation).

\section{Statistical analysis}

Data were expressed as numbers or means +/- standard deviation or numbers as appropriate using SPSS software version 20.0.

\section{Results and Discussion}

The results for the influence of PMF on the MERS-CoV virus is shown in Figure 1 and Supplementary file S1. The analysis included one control test in which the amount of input virus at $37^{\circ} \mathrm{C}$ was estimated to be $\lg$ ID50 $=6.13 \pm 0.34$ after 60 min. After $240 \mathrm{~min}$, virus titer was declined to $\lg$ ID50 $=5.52 \pm 0.32$ due to the influence of temperature $(\Delta$ virus titer $=0.61 \pm 0.46)$. With the Lycke's method, a sample dilution was done $(\mathrm{VF}=1000)$. With that dilution, no cytotoxicity was visible and the susceptibility of the detection cells was given $(\Delta$ titer $=0.18 \pm 0.47)$. With PMF final test concentration of $20.34 \%$, the virus reduction factor (RF) was estimated to be $4.31 \pm 0.48$ after $60 \mathrm{~min}$. After the exposure time was prolonged to $240 \mathrm{~min}$, no residual virus could be detected. The corresponding virus reduction factor was estimated to be $>5.50 \pm 0.45$ corresponding to a virus reduction of $99.999 \%$ (Supplementary file S1).

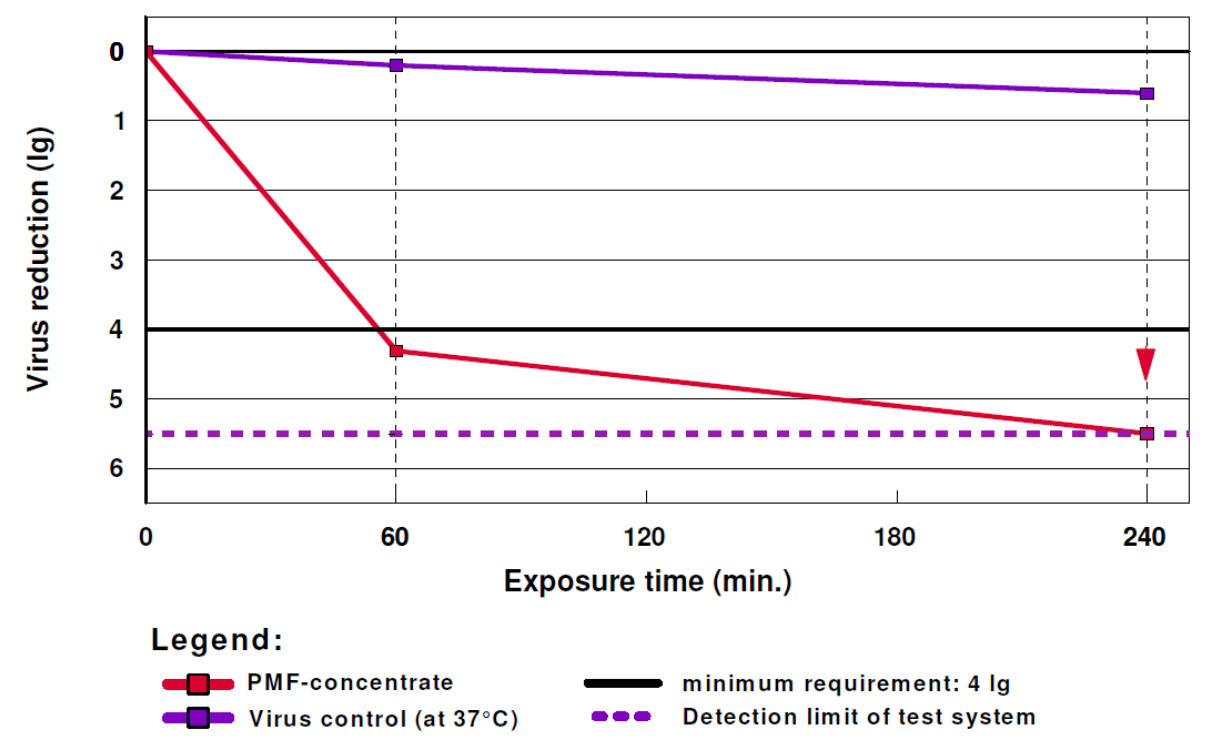

Figure 1. MERS-CoV virus reduction ( $\mathrm{lg}$ ) as affected by the treatment of camel urine fraction $(P M F)$ and measured after 60 and 240 min. Virus reduction = titer of virus control minus titer of sample $\left(\lg I D_{50}\right)$ 
The results for the influence of PMF on the H1N1 virus is shown in Figure 2 and Supplementary file S2. The analysis included two control tests. Screening test S1 indicated that the $\mathrm{pH}$ of the 1.25 fold concentrated working solution were measured to $\mathrm{pH} 9.54$, which was changed only slightly to $\mathrm{pH} 9.52$. The amount of input virus at $37^{\circ} \mathrm{C}$ was estimated to be $\lg \operatorname{ID} 50=4.47 \pm 0.36$ after $60 \mathrm{~min}$ and to $\mathrm{lg}$ ID50 $=4.38 \pm 0.23$ after $240 \mathrm{~min}(\Delta$ virus titer $=0.10 \pm 0.42)$. Using the Spearman \& Kärber's titration method, a cytotoxicity titer of $\lg$ TD50 $=2.45$ was recorded for the test samples. This is equivalent with the detection limit of this screening test. Screening test S2 indicated that the amount of input virus at $37^{\circ} \mathrm{C}$ was estimated to be $\mathrm{lg}$ ID50 $=4.88 \pm 0.26$ after $60 \mathrm{~min}$ and to $\lg$ ID50 $=4.88 \pm 0.39$ after $240 \mathrm{~min}(\Delta$ virus titer $=0)$. With the Lycke's method, a sample dilution was done (VF $=1000)$. With that dilution, no cytotoxicity was visible and the susceptibility of the detection cells was given $(\Delta$ titer $=0.18 \pm 0.53$ ). In addition, the detection limit of this screening test could be improved by $2.45 \mathrm{Log}$. Virus inactivation in this screening test indicated that $20.34 \%$ of PMF (final test concentration) resulted in virus reduction factor of $2.28 \pm 0.48$ after $60 \mathrm{~min}$. After $240 \mathrm{~min}$, no residual virus could be detected (test virus below detection limit, due to product associated cytotoxicity [lg TD50 $=2.45]$ ). The corresponding virus reduction factor was estimated to be $1.93 \pm 0.23$. For the second screening test, $20.34 \%$ of PMF (final test concentration) resulted in the virus reduction factor of $1.62 \pm 0.37$ after $60 \mathrm{~min}$.

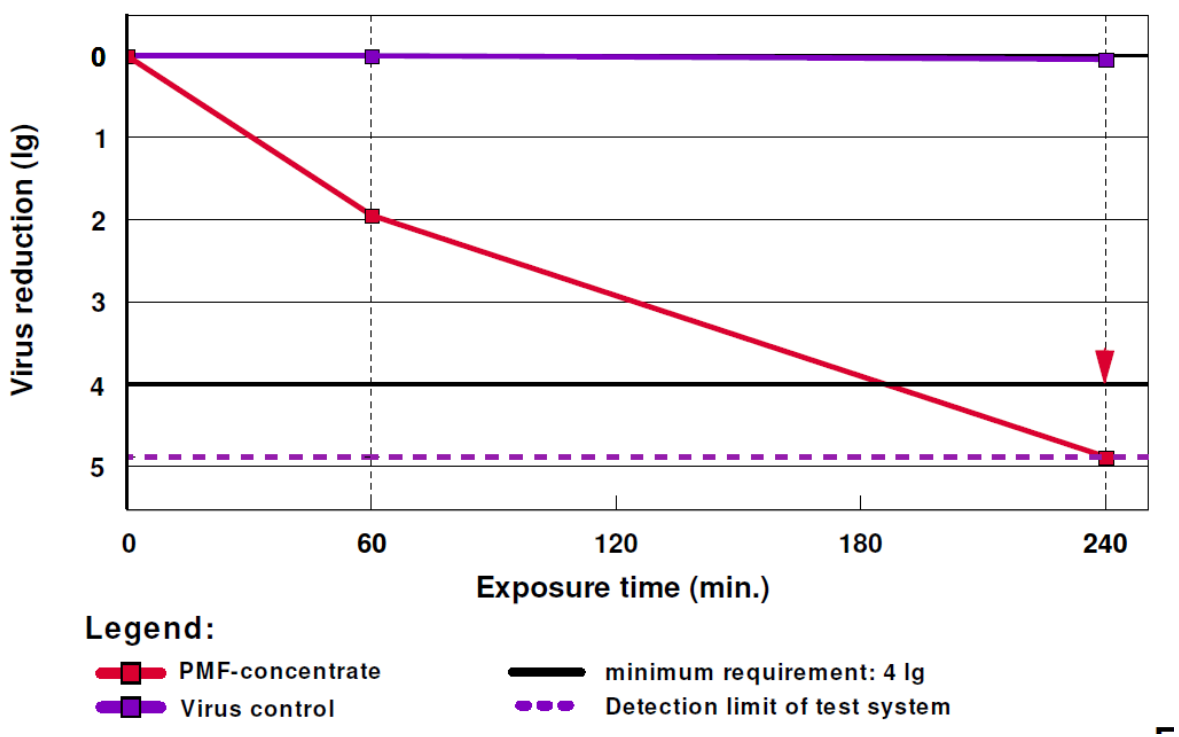

Figure 2. H1N1 virus reduction ( $\mathrm{lg}$ ) as affected by the treatment of camel urine fraction (PMF) and measured after 60 and $240 \mathrm{~min}$. Virus reduction = titer of virus control minus titer of sample $\left(\lg I D_{50}\right)$

After $240 \mathrm{~min}$, no residual virus could be detected. The corresponding virus reduction factor was estimated to be $>4.88 \pm 0.55$ corresponding to a virus reduction of 99.998\% (Supplementary file S2).

The overall results indicated that PMF is a promising bio-product derived from camel urine with antiviral potentials. However, the mechanism of action is yet to be deciphered. Many viral diseases have associated with high morbidities and mortalities, and new approaches should be presented to find a cure. Many identified antiviral drugs 
have also been used as anticancer agents in which drugs are effective in preventing DNA synthesis. The lyophilized PM701 extracted fraction from camel urine at 150 $\mathrm{mg} / \mathrm{g}$ inhibited cancer cells proliferation without damaging normal cells at cell culture level (Khorshid et al., 2011; Mahboub et al., 2015). The MDCK reporter cell line established in this study is highly permissive for influenza virus replication and provides a highly specific and sensitive approach for simultaneous detection and isolation of influenza viruses (Hossain et al., 2010). Yao and coworkers (2014) had described that anti-herpes simplex virus drug (acyclovir) is an effective agent for cancer treatment. Camel urine was proven to induce cytotoxic influence in major types of human cancer cell lines (El-Shahawy et al., 2010; Al-Yousef et al., 2012). It was evident that the anticancer properties of camel's urine can be performed as antiviral properties. Anticancer properties were not attributed to a given compound in the camel's urine, such as zinc, copper and amino acids (Khorshid et al., 2009; Raouf et al., 2009; Ahmed et al., 2010; Ali et al., 2011). Jannah and coworkers also described that zinc and copper are the two key elements in PMF that delivers its antimicrobial effect (Jannah et al., 2013). Zinc has been proven to have antiviral activities against TGEV by viral multiplication within cells via inhibiting protein but it has no effect on cell infection (Weia et al., 2012). Sunada and colleagues conducted their study on bacteriophages and concluded that copper ion reduced infectious ability of phages (Sunada et al., 2012). Therefore, both copper and zinc are thought to have a vital role in antiviral and virostatic activity of PMF used in the present study. The high antimicrobial effect of crude extracts of camel urine was speculated to be due to its high osmolarity, high levels of proteins and potassium metallic ions (Stankova et al., 2009; Khorshid et al., 2011). Khorshid and coworkers (El-Shahawy et al., 2010; Khorshid et al., 2011; Mahboub et al., 2015) recorded that camel urine had cytotoxicity only against various human cancer cell lines, with negligible effect on non-tumorigenic epithelial and fibroblast cells (Khorshid et al., 2005, 2015). Several studies have also successfully proven the anticancer, antibacterial and antifungal effects of PMF (Khorshid et al., 2011, 2015; Mahboub et al., 2015).

Up to date, there are no effective treatments against human coronaviruses infections that has high mortality rate of up to $40 \%$ (Feikin et al., 2015). The American Academy of Pediatrics (2017-2018) indicated the recommendations for prevention and control of $\mathrm{N} 1 \mathrm{H} 1$ by the use of trivalent, rather than the quadrivalent live attenuated influenza vaccine, containing the A/Michigan/45/2015 (H1N1) pdm09-like virus. The report indicated that antiviral medication in children can be important in controlling the disease, but this cannot be a substitute for vaccination. Our results indicate that PMF might be used solely as a potential alternative cure of the disease.

The present study highlighted the virucidal activity of PMF against the two viruses with no observed effects on the control. These results suggested that PMF treatment has an in vitro powerful effect on the virus replication process at the cellular level. The antiviral activity mode of action of camel urine fraction PMF has not been identified. Therefore, more investigations are needed concerning gene expression profiling to investigate the apoptotic activity of PMF. The antiviral activity of PMF should be enhanced for fast promising therapy using a wide range of DNA and RNA virus models as well as cancer inducing viruses. 


\section{Conclusion}

The MERS-CoV and H1N1 viral infections, identified in the Middle East, have global concerns because of their associated high morbidity and mortality. The results of in-vitro PMF treatment showed a significant reduction in the titers of the two viruses across time indicating that PMF has potential antiviral activities. More studies are recommended to fractionate and monitor the antiviral activity of PMF compositions and to determine molecular mechanisms of action.

Acknowledgments. The authors acknowledge GCC patents office for granted this project GCC Patent No. GC0002755 and European patent office for granted Europe patent No. 2263681. The authors also acknowledge Engineer Musab Alyasin for pear for the cost of transporting and testing of PMF; Professor Enas A Hamed, Professor of Physiology, Faculty of Medicine, Assiut University, Assiut, Egypt for critical reading of the manuscript.

\section{REFERENCES}

[1] Ahmed, G. A., Khorshid, F. A., Kumosani, T. A. (2010): FT-IR spectroscopy of A549 cells treated with PMF: structural changes in DNA and cell membrane. - J. Thoracic Onco. 5: 46S.

[2] Al-Bashan, M. M. (2011): In vitro assessment of the antimicrobial activity and biochemical properties of camel's urine against some human pathogenic microbes. Middle-East J. Sci. Res. 7: 947-958.

[3] Alghamdi, Z., Khorshid, F. A. (2012): Cytotoxicity of the urine of different camel breeds on the proliferation of lung cancer cells, A549. - J. Nat. Sci. Res. 2: 9-16.

[4] Ali, A., Khorshid, F. A., Aboarky, H., Osman, A. M. (2011): Tumor lung cancer model for assessing anti-neoplastic effect of PMF in rodents: histopathological study. - Trends in Appl. Sci. Res. 6: 1214-1221.

[5] Al-Yousef, N., Gaafar, A., Al-Otaibi, B., Al-Jammaz, I., Al-Hussein, K., Aboussekhra, A. (2012): Camel urine components display anti-cancer properties in vitro. - J. Ethnopharmacol. 143: 819-825.

[6] American Academy of Pediatrics: Recommendations for prevention and control of influenza in children (2017-2018). - Pediatirics 140: e20172550.

[7] Assiri, A., McGeer, A., Perl, T. M., Price, C. S., Al Rabeeah, A. A., Cummings, D. A. T., Alabdullatif, Z. N., Assad, M., Almulhim, A., Makhdoom, H., Madani, H., Alhakeem, R. (2013): Hospital outbreak of Middle East respiratory syndrome coronavirus. - N. Engl. J. Med. 369: 407-416.

[8] Belouzard, S., Millet, J. K., Licitra, B. N., Whittaker, G. R. (2012): Mechanisms of coronavirus cell entry mediated by the viral spike protein. - Viruses 4: 1011-1033.

[9] de Groot, R. J., Baker, S. C., Baric R. S., Brown, C. S., Drosten, C., Enjuanes, L., Fouchier, R. A. M., Galiano, M., Gorbalenya, A. E., Memish, Z. A., Perlman, S., Poon, L. L. M., Snijder, E. J., Stephens, G. M., Woo, P. C. Y., Zaki, A. M., Zambon, M., Ziebuhr, J. (2013): Middle East respiratory syndrome coronavirus (MERS-CoV): announcement of the coronavirus study group. - J. Virol. 87: 7790-7792.

[10] Drosten, C., Seilmaier, M., Corman, V. M., Hartmann, W., Scheible, G., Sack, S., Guggemos, W., Kallies, R., Muth, D., Junglen, S., Müller, M. A., Haas, W., Guberina, H., Röhnisch, T., Schmid-Wendtner, M., Aldabbagh, S., Dittmer, U., Gold, H., Graf, P., Bonin, F., Rambaut, A., Wendtner, C. M. (2013): Clinical features and virological analysis of a case of Middle East respiratory syndrome coronavirus infection. - Lancet Infect. Dis. 13: 745-751. 
[11] Du, L., Yang, Y., Zhou, Y., Lu, L., Li, F., Jiang, S. (2017): MERS-CoV spike protein: a key target for antivirals. - Expert Opin. Ther. Targets 21: 131-143.

[12] El-Shahawy, A., Elsawi, N. M., Baker, W. S., Khorshid, F. A., Neveen, A., Geweely, N. (2010): Spectral analysis, molecular orbital calculations and antimicrobial activity of PMF-G fraction extracted from PM-701. - Int. J. Pharma. Biosci. 1: 1-19.

[13] Feikin, D. R., Alraddadi, B., Qutub, M., Shabouni, O., Curns, A., Oboho, I. K., Tomczyk, S. M., Wolff, B., Watson, J. T., Madani, T. A. (2015): Association of higher MERS-CoV virus load with severe disease and death, Saudi Arabia, 2014. - Emerg. Infect. Dis. 21: 2029-2035.

[14] Frieman, M. (2014): The art of war: battles between virus and host. - Curr. Opin. Virol. 6: 76-77.

[15] Getachew Alebie, G., Yohannes, S., Worku, A. (2017): Therapeutic applications of camel's Milk and urine against cancer: current development efforts and future perspectives. - J. Cancer Sci. Therapy 9: 5.

[16] Hossain, M. J., Perez, S., Guo, Z., Chen, L. M., Donis, R. O. (2010): Establishment and characterization of a Madin-Darby canine kindey reported cell for influenza A virus assays. - J. Clin. Microbiol. 48: 2515-2523.

[17] Jannah, H., Ali, A. S., Efat, M. M., Khorshid, F. A. (2013): An ointment contains pmf showed promising results for treatment of psoriasis in human. - Intl. J. Med. Appl. Sci. 2: $15-20$.

[18] Khorshid, F. A., Moshref, S. S., Heffny, N. (2005): An ideal selective anticancer agent in vitro, I- tissue culture study of human lung cancer cells A549. - JKAU- Med. Sci 12: 318.

[19] Khorshid, F. A. (2008): Preclinical evaluation of PM 701 in experimental animals. - Intl. J. Pharmacol. 1: 443-451.

[20] Khorshid, F. A. (2009): Potential anticancer natural product against human lung cancer cells. - Trends in Med. Res. 4: 9-15.

[21] Khorshid, F. A., Osman, A. A., Abdulsattar, E. (2009): Cytotoxicity of bioactive fractions from PM 701. - EJEAFChe 8: 1091-1098.

[22] Khorshid, F. A., Rahimaldeen, S. A., Alameri, J. S. (2011): Apoptosis study on the effect of PMF on different cancer cells. - Intl. J. Biol. Chem. 5: 150-155.

[23] Khorshid, F. A., Rabah, S., As, A., Noor, S. O., Alkabkaby, H. (2015): Safety of oral administration of PMF a fraction derived from camel urine: acute study on mice. - Intl. J. Emerg. Technol. Adv. Engineer. 6: 365-370.

[24] Kong, W., Wang, F., Dong, B., Ou, C., Meng, D., Liu, J., Fan, Z. C. (2015): Novel reassortant influenza viruses between pandemic (H1N1) 2009 and other influenza viruses pose a risk to public health. - Microb. Pathog. 89: 62-72.

[25] Lim, B. H., Mahmood, T. A. (2011): Influenza A H1N1 2009 (Swine Flu) and pregnancy. - J. Obstet. Gynaecol. 61: 386-393.

[26] Lin, S. C., Ho, C. T., Chuo, W. H., Li, S., Wang, T. T., Lin, C. C. (2017): Effective inhibition of MERS-CoV infection by resveratrol. - BMC Infect. Dis. 17: 144.

[27] Mahboub, F. A., Khorshid, F. A., Emwas, A. M. (2015): The cytotoxic effect of small and large molecules of PMF fraction extracted from camel urine on cancer cells. - British J. Med. Med. Res. 6: 384-396.

[28] Morens, D. M., Fauci, A. S. (2007): The 1918 influenza pandemic: insights for the $21^{\text {st }}$ century. - J. Infect. Dis. 195: 1018-1028.

[29] Müller, C., Ulyanova, V., Ilinskaya, O., Pleschka, S., Mahmud, R. S. (2017): A Novel antiviral strategy against MERS-CoV and $\mathrm{HCoV}-229 \mathrm{E}$ using Binase to target viral genome replication. - BioNanoScience 7: 294-299.

[30] Raouf, G. A., Khorshid, F. A., Kumosani, T. (2009): FT-IR spectroscopy as a tool for identification of apoptosis-induced structural changes in A549 cells dry samples treated with PM 701. - Intl. J. Nano Biomaterials 2: 396-408. 
[31] Stankova, I., Chuchkov, K., Shishkov, S., Kostova, K., Mukova, L., Galabov, A. S. (2009): Synthesis, antioxidative and antiviral activity of hydroxycinnamic acid amides of thiazole containing amino acid. - Amino Acids 37: 383-388.

[32] Sunada, K., Minoshima, M., Hashimoto K. (2012): Highly efficient antiviral and antibacterial activities of solid-state cuprous compounds. - J. Hazard, Mater. 235-236: 265-270.

[33] Taubenberger, J. K., Reid, A. H., Lourens, R. M., Wang, R., Jin, G., Fanning, T. G. (2005): Characterization of the 1918 influenza virus polymerase genes. - Nature 437: 889-893.

[34] Taubenberger, J. K., Hultin, J. V., Morens, D. M. (2007): Discovery and characterization of the 1918 pandemic influenza virus in historical context. - Antivir. Ther. 12: 581-591.

[35] The Economist (2014): Livestock insurance in Kenya: no risk, no reward. Economist.com.

[36] van der Hoek, L., Pyrc, K., Jebbink, M. F., Vermeulen-Oost, W., Berkhout, R. J., Wolthers, K. C., Wertheim-van Dillen, P. M., Kaandorp, J., Spaargaren, J., Berkhout, B. (2004): Identification of a new human coronavirus. - Nature Med. 10: 368-373.

[37] Wei, Z., Burwinkel, M., Palissa, C., Ephraim, E., Schmidt, M. F. (2012): Antiviral activity of zinc salts against transmissible gastroenteritis virus in vitro. - Veterinary Microbiol. 160: 468-472.

[38] World Health Organization (WHO) (2014): Middle East respiratory syndrome coronavirus (MERS-CoV) summary and literature update - as of 20 January 2014. [cited 2014 Feb 20]. http://www.who.int/csr/disease/coronavirusinfections/ MERS CoV 2014.

[39] Yao, J., Zhang, Y., Ramishetti, S., Wang, Y., Huang, L. (2014): Turning an antiviral into an anticancer drug: Nanoparticle delivery of acyclovir monophosphate. - J. Controlled Release 170: 414-420.

[40] Zaki, A. M., van Boheemen, S., Bestebroer, T. M., Osterhaus, A. D., Fouchier, R. A. (2012): Isolation of a novel coronavirus from a man with pneumonia in Saudi Arabia. New Engl. J. Med. 367: 1814-1820. 